\title{
POWER AND AUTHORITY DI PONDOK PESANTREN: POTRET KEPEMIMPINAN KIAI DALAM LINGKUNGAN MULTIKULTURAL
}

\author{
Akhmad Munir \\ Universitas Jember \\ akhmadmunir@unej.ac.id
}

\begin{abstract}
Abstrak
Artikel ini mencoba mengeksplorasi konsepsi kepemimpinan kiai di pondok pesantren dalam konteks kekuasaan (power) dan otoritas (authority) dalam lingkungan yang multikultural (multicultural environment). Kepemimpinan merupakan seni memengaruhi (the art of influence) agar orang melakukan sesuai dengan tujuan yang diinginkan. Kekuasaan (power) adalah kesempatan bagi manusia atau sekelompok manusia untuk menyadarkan individu atau kelompokindividulainnya terhadap kemauan yang diinginkan. Kekuasaan menjelma dalam ragam bentuk, seperti: pengaruh, persuasi, manipulasi, kekuatan (force), dan koersi. Sedangkan otoritas merupakan wewenang yang diberikan kepada seseorang atau kelompok atau instansi secara sah agar patuh terhadapnya karena didukung oleh norma dan peraturan yang dibuat. Jadi, kekuasaan terkait erat dengan kemampuan; sedangkan otoritas merupakan hak untuk mengambil tindakan yang diperlukan agar tugas dan tanggungjawab dapat dilaksanakan secara efektif dan efisien. Produktivitas kekuasaan dan otoritas selalu berjalan dinamis di dalam lingkungan multikultural. Konsepsi kepemimpinan dalam konteks lingkungan multikultural inilah yang dipraktekkan oleh founding fathers bangsa kita dulu.
\end{abstract}

Kata Kunci: kekuasaan, kepemimpinan kiai, lingkungan multikultural, otoritas, pondok pesantren 


\begin{abstract}
The article is trying to explore the concept of leadership of kiai in pesantren (Islamic boarding school) in the context of power and authority on multicultural environment. Leadership is the art of influence in order to be acted by others in accordance with what he or she wants others do. Power is an opportunity for human being or community to make individual or others aware to the willingness of what he wants. Power incarnates to various forms, for instance: influence, persuasion, manipulation, force as well as coercion. On the other hand, the authority is a right given to someone or community or institution legally in order to obey because of the rules and norms as well that made. So, power is related to capability; the authority is a right to make decision as needed so that the task or assignment as well as responsibility can be carried out effectively and efficiently. The productivity of power and authority is on the tract dynamically in the context of multicultural environment. This concept of leadership in the context of multicultural environment had been practiced by our founding fathers.
\end{abstract}

Keywords: power, leadership of kiai, multicultural environment, authority, pondok pesantren

\title{
Pendahuluan
}

Konsepsi kepemimpinan telah berkembang dari waktu ke waktu. Dengan mengutip Crainer (1996), Raihani ${ }^{1}$ menggambarkan evolusi teori-teori kepemimpinan dengan sembilan klasifikasi yaitu teori the great man, pembawaan, kekuasaan dan pengaruh, behavioris, situasional, kontingental, transaksional, atribusi (penyifatan), dan teori transformasional. Klasifikasi ini menunjukkan dengan jelas adanya perubahan yang terus menerus tentang konsepsional kepemimpinan. Perubahan ini bukan hanya disebabkan oleh keterbatasan teori sebelumnya di dalam menjawab persoalan-persoalan yang ada melainkan juga karena adanya ragam perspektif yang terus berkembang.

Kepemimpinan bisa diartikan sebagai proses mempengaruhi orang yang terlibat di dalamnya dengan upaya mencapai tujuan organisasi. Kepemimpinan bertitik tolak pada sistem bukan individu. Ada juga yang mengartikannya sebagai social influence process of involving two or more people. Warren Bennis mengartikan

'Raihani, Kepemimpinan Sekolah Transformatif (Yogyakarta: LKiS, 2010), 11. 
kepemimpinan sebagai fungsi mengetahui diri sendiri, punya visi yang bisa dipahami dan dikomunikasikan, membangun kepercayaan di antara koleganya, dan bertindak secara efektif untuk merealisasikan potensi kepemimpinannya. ${ }^{2}$

Semua pemahaman tentang kepemimpinan di atas bermuara pada satu frase, yaitu seni mempengaruhi atau the art of influence agar orang lain mengikuti apa yang menjadi tujuannya. Jadi hakekat kepemimpinan adalah seni (leadership is art). Karena itu, persoalan kepemimpinan merupakan persoalan yang dinamis. ${ }^{3}$ Demikian pula, pemahaman masalah pengaruh (influence). Seberapa besar pengaruh seseorang sebenarnya menunjukkan seberapa besar sifat kepemimpinannya. Dalam konteks organisasi, kepemimpinan yang berpijak pada pengaruh ini dibangun berdasarkan sistem (leadership based on the system not the person), yang dibangun secara bersama-sama.

Bagaimana mempengaruhi ini kemudian melahirkan tipetipe atau model kepemimpinan ${ }^{4}$. Ada banyak dalam hal ini seperti kepemimpinan melayani (servant leadership) dengan salah satu tokoh utamanya adalah Robert Greenleaf atau kepemimpinan nurani dengan salah satutokohnya adalah Parker J. Palmer (leading from within). Robert Greenleaf beranggapan bahwa pemimpin yang melayani merupakan orang yang menyelesaikan misi organisasi dengan menyerasikan visi yang berkesinambungan serta membuat orang terbantu dan paham dengan peran, fungsi, dan tanggungjawabnya dalam melakukan tugas dengan keharmonisan bersama visi implisitnya. ${ }^{5}$

${ }^{2}$ Leadership is a function of knowing yourself, having a vision that is well communicated, building trust among colleagues, and taking effective action to realize your own leadership potential. Lihat: Warren Bennis,On Becoming a Leader dan An Invented Life: Reflections on Leadership and Change. (Perseus Publishing, USA, 1994).

3 Catatan kuliah Prof. H. Khusnuridlo, M.Pd. pada saat kuliah program Doktor Manajemen Pendidikan Islam di IAIN Pascasarjana dengan pokok bahasan "Kepemimpinan Spiritual dalam Islam: Refleksi Teologis tentang Power and Authority dalam Pendidikan Islam" pada Jumat, 29 Maret 2019.

4 Pribadi Surya mengklasifikasikan tentang tipe kepemimpinan dalam dunia pendidikan ke dalam empat tipe, yaitu: otoritarian, Laissez-Faire, demokratik, dan pseudo-demokratik. Lihat Pribadi Surya Educational Management: Handbook for School of Education Student (Yogyakarta: Yogyakarta State University, 2011), 23.

5 "The servant leader is the actor that accomplishes the mission of organisation in consonance with a sustainable vision and who helps people to 


\section{Pembahasan}

Teori tentang kepemimpinan ${ }^{6}$ dapat dibedakan ke dalam tiga fase, yaitu fase awal, pertengahan, dan baru. Fase yang pertama merupakan fase yang didominasi oleh awal mula teori tentang kepemimpinan. Awal mula teori tentang kepemimpinan berbicara masalah teori Great Man. Bahwa pemimpin itu hanya dilahirkan untuk menjadi pemimpin, kualitas kepemimpinannya memang sudah meleat sejak lahir. Jadi orang menjadi pemimpin karena dia memang sudah given ciri dan sifat kepemimpinannnya. Kedua adalah fase pertengahan. Di dalam fase ini ada teori fungsional, behavioristik, dan situasional. Teori Fungsional disampaikan oleh John Adair (1970) dalam karyanya Action Centred Leadership. Pemimpin berhubungan demgan interaksi tiga area, yaitu tugas (seting tujuan, metode, dan proses), tim (interaksi yang efektif, komunikasi yang efektif, peran, moralitas tim), dan individual (perhatian kepada prilaku, perasaan, mentoring, dan sebagainya) ${ }^{7}$

Ada juga teori behavioristik oleh Blake and Mouton (1964) dalam karyanyaManagerial grid. Ada tiga dalam teori ini, yaitu:pertama, prilaku dan tindakan pemimpin, dari pada ketrampilan yang dimilikinya seperti orientasi produksi atau orientasi orang. Kedua, Prilaku kepemeimpinan yang berbeda dikategorikan sebagai gaya kepemimpinan, seperti: otokratik, persuasif, konsultatif, democratik. Ketiga, tidak menyediakan panduan untuk mengefektifkan kepemimpinannya dalam situasi yang berbeda. Berikutnya adalah teori kepemimpinan situasional atau kontingensi dengan salah satu tokohnya Hersey-Blanchard, 1970/80. Gaya kepemimpinan berubah sesuai dengan situasinya dan

understand their roles and responsibilities, doing their job in harmony with an explicit or implicit vision”. Lihat: BURLEA ŞCHIOPOIU A., RAINEY S., Servant lider/Servant leadership, in Encyclopedia of Corporate Social Responsibility, Editor-in-Chief Samuel O. Idowu, (Heidelberg: Springer-Verlag Berlin, 2013), 2120-2126.

6 R. Bolden, J. Gosling, A. Marturano, dan Dennison. 2003. The Leadership Theories, 31 dalam "The Leadership for Instructional Improvement" (IAIN Jember Press, 2015). Dalam buku ini dijelaskan tentang teori kepemimpinan dari great man theories, trait teories, behaviorist theories, situational leadership, contingency theories, transactional theory, dan transformational theory. House, 1970).

7 John Adair, Action Centred Leadership, (Mumbai: Jaico Publishing 
dalam respon terhadap individu yang diatur, kompetensi dan motivasi mereka.

Kemudian yang ketiga adalah fase teori kepemimpinan yang masih baru. Teori kepemimpinan yang baru yaitu teori transformasional (Bass and Avolio, 1994). Dalam teori kepemimpinan model ini adalah: pertama, pemimimpin menginspirasi individu-individu yang ada, membangun kepercayaan, dan menggali kreatifitas dan pertumbuhan personal. Kedua, individua-individumengembangakn rasa focus pada tujuan untuk mengahsilkan benefit kepada organisasi dan masyarakat. Hal ini melampaui kepentingan dirinya sendiri dan merubah penghargaan untuk upaya dan loyalitas. Menurut Leithwood (1999:9) sebagaimana dikutip oleh Tony Bush dalam karyanya "Educational Leadership and Management: Theory, Policy, and Practice ${ }^{8}$ mengatakan bahwa kepemimpinan transformasional mengasumsikan bahwa fokus utama kepemimpinan adalah komitmen dan kapasitas anggota organisasi. Level lebih tinggi dari komitmen personal terhadap tujuan organisasi dan kapasitas yang lebih besar untuk menyelesaikan tujuan ini diasumsikan dapat menghasilkan produktifitas yang lebih besar. Tabel di bawah ini mengilustrasikan kepemimpinan transformasional.

Tabel 1: Kepemimpinan Transformasional

\begin{tabular}{|c|c|c|c|c|}
\hline Kompetensi & $\begin{array}{l}\text { Kompetensi } \\
\text { Rendah }\end{array}$ & Kompetensi & $\begin{array}{c}\text { Kompetensi } \\
\text { Tinggi }\end{array}$ & $\begin{array}{c}\text { Kompetensi } \\
\text { Tinggi }\end{array}$ \\
\hline \multirow[t]{2}{*}{ Motivasi } & $\begin{array}{l}\text { Komitment } \\
\text { rendah/ }\end{array}$ & $\begin{array}{l}\text { Variable } \\
\text { Komitmen/ }\end{array}$ & \multirow{2}{*}{$\begin{array}{l}\text { Variable } \\
\text { Komitmen/ } \\
\text { Mampu } \\
\text { namun tidak } \\
\text { ada kemauan }\end{array}$} & $\begin{array}{l}\text { Kommitmen } \\
\text { Tinggi/ }\end{array}$ \\
\hline & $\begin{array}{l}\text { Tidak mampu } \\
\text { dan tidak ada } \\
\text { kemauan }\end{array}$ & $\begin{array}{l}\text { Tidak mampu } \\
\text { namun niat } \\
\text { atau } \\
\text { termotivasi }\end{array}$ & & $\begin{array}{l}\text { Mampu dan } \\
\text { penuh } \\
\text { motivasi }\end{array}$ \\
\hline $\begin{array}{c}\text { Gaya } \\
\text { Kepemim- } \\
\text { pinan }\end{array}$ & $\begin{array}{l}\text { Mengarahkan } \\
\text { (cerita) }\end{array}$ & $\begin{array}{l}\text { Mendampingi } \\
\text { (Menjajakan) }\end{array}$ & $\begin{array}{l}\text { Mendukung } \\
\text { (partisipasi) }\end{array}$ & $\begin{array}{l}\text { Delegasi } \\
\text { (observasi) }\end{array}$ \\
\hline
\end{tabular}

Kepemimpinan transformasional adalah model kepemimpinan yang berangkat dari keinginan kuat untuk

${ }^{8}$ Tony Bush. 2007. Educational Leadership and Management: Theory, Policy, and Practice dalam "The Leadership for Instructional Improvement" (IAIN Jember Press, 2015). 
mentransformasikan organisasi menuju perubahan dan perbaikan. Fokusnya untuk mewujudkan visi organisasi dengan melakukan transformasi visi amggota organisasi agar bedampak terhadap terwujudnya visi dan misi organisasi. 9 Kepemimpinan ini merupakan proses dimana seorang individu mempengaruhi sekelompok individu untuk mencapai suatu tujuan. Untuk menjadi seorang pemimpin yang efektif, seorang Kepala Sekolah, misalnya, harus dapat mempengaruhi seluruh warga sekolah yang dipimpinnya melalui cara-cara yang positif untuk mencapai tujuan pendidikan di sekolah. Secara sederhana kepemimpinan transformasional dapat diartikan sebagai proses untuk mengubah dan mentransformasikan individu agar mau berubah dan meningkatkan dirinya, yang didalamnya melibatkan motif dan pemenuhan kebutuhan serta penghargaan terhadap para bawahan.

Dalam hal ini terdapat empat faktor untuk menuju pada kepemimpinan tranformasional, yaitu: pengaruh yang diidealkan (idealized influence), motivasi yang inspiratif (inspirational motivation), stimulasi intelektual (intellectual stimulation), dan pertimbangan individu (individual consideration).

Pertama adalah pengaruh yang diidealkan. Dalam konteks lembaga pendidikan, Kepala Sekolah merupakan sosok ideal yang dapat dijadikan sebagai panutan bagi guru dan karyawannya, dipercaya, dihormati dan mampu mengambil keputusan yang terbaik untuk kepentingan sekolah. Kedua adalah motivasi yang inspiratif.Kepala Sekolah dapat memotivasi seluruh guru dan karyawannnya untuk memiliki komitmen terhadap visi organisasi dan mendukung semangat team dalam mencapai tujuan-tujuan pendidikan di sekolah. Ketiga adalah stimulasi intelektual. Kepala Sekolah dapat menumbuhkan kreativitas dan inovasi di kalangan guru dan stafnya dengan mengembangkan pemikiran kritis dan pemecahan masalah untuk menjadikan sekolah ke arah yang lebih baik. Yang terakhir adalah pertimbangan individu. Kepala Sekolah dapat bertindak sebagai pelatih dan penasihat bagi guru dan stafnya.

Di dalam disiplin ilmu sosiologi, kekuasaan tidak dipandang sebagai sesuatu yang bernilai baik atau buruk. Ini bukan persoalan nilai. Namun adanya kekuasaan merupakan unsur

\footnotetext{
${ }^{9}$ Mohammad Karim, Pemimpin Transformasional di Lemabga Pendidikan Islam, (Malang: UIN Maliki Press, 2010), 4.
} 
penting dalam kehidupan suatu masyarakat. Kekuasaan selalu ada di dalam masyarakat baik dalam bentuknya yang sederhana maupun yang kompleks. Adanya kekuasaan tergantung dari hubungan antara yang berkuasa dan yang dikuasai. Adanya kekuasaan juga tergantung pada pihak yang memiliki kemampuan untuk melancarkan pengaruh dan pihak lain yang menerima pengaruh itu, dengan rela atau karena terpaksa. Apabila kekuasaan menjelma pada seorang individu maka individu itu dinamakan sebagai pemimpin.

Kekuasaan dapat dipahami sebagai kesempatan bagi individu atau sekelompok manusia untuk menyadarkan individu lainnya atau kelompok lainnya terhadap kemauan yang diinginkannya sekaligus pada saat yang ebrsamaan menerapkannya pada orang-orang yang sedang atau akan melakukan perlawanan kepadanya. Atau dengan kata lain, kekuasaan merupakan kemampuan untuk membuat orang lain patuh dan menjalankan terhadap apa yang dikehendaki; bisa pula bermakna kecenderungan seseorang untuk berprilaku sesuai dengan kehendaknya. Hal ini bersifat alamiah karena pada hakekatnya manusia sebagai makhluk social tidak bisa dilepaskan dari kepentingan dirinya dari orang lain. Konsep kekuasaan bisa timbul karena adanya perbedaan makna meskipun tujuannya sama. Penjelamaan atau bentuk kekuasaan dapat mengejewantah dalam hal, seperti: pengaruh, persuasi, manipulasi, kekuatan (force), dan koersi.

Pertama adalah pengaruh(influence). Pengaruh merupakan kondisi social-psikologis yang tunduk dan patuh pada kekuasaan. Semakin kuat pengaruh maka semakin powerful kekuasaan seorang pemimpin. Yang kedua adalahpersuasi (persuation). Seorang pemimpin yang berkuasa sudah semestinya dia mempunyai kekuatan untuk melakukan persuasi. Persuasi merupakan keuatan emosional dalam meyakinkan kondisi di sekitarnya termasuk individu-individu yang terkait di dalamnya. Yang ketiga adalahmanipulasi (manipulation). Pemimpin yang berkuasa meniscayakan adanya manipulasi. Monopoli infomrasi dan sarana kekuasaaan yang ada menyebabkan tafsir sepihak sering terjadi. Karena adanya penguasaan informasi dan sarana inilah kerapkali menimbulkan manipulasi. Sedangkan yang terakhir adalah memaksa (coertion/ force). Koersi dalam hal ini bersifat memaksa. Buku Politic as a Vocation dianggap sebagai dasar filsafat politik Weber. Dalam buku ini, Weber mengawalinya dengan konsep 
tentang Negara (state). Negara dalam pandangan Weber mempunyai alat atau saarana yang dimilikinya. Dia mengatakan "the state is a human society that (successfully) claims the monopoly of the legitimate use of physical force within a given territory. Negara adalah sebuah masyarkat manusia yang dibenarkan memonopoli penggunaan kekuatan memaksa secara fisik di dalam suatu wilayah tertentu. Menurut Weber, Negara tidak pening untuk dilihat dari segi tujuannya namun lebih pada sarana apa yang dimilikinya. Saranaa dalam hal ini adalah dimonopolinya penggunaan kekuatan memaksa secara fisik. Negara dalam hal ini kemudian menjadi sumber utama dibenarkannya penggunaan kekerasan.

Otoritas merupakan wewenang yang diebrikan kepada seseorang atau komunitas atau instansi secara sah agar patuh terhadapnya karena didukung oleh norma dan peraturan yang dibuat. Hal ini bersifat alamiah karena pada hakekatnya manusia sebagai makhluk sosial tidak bisa dilepaskan dari kepentingan dirinya dari orang lain. Otoritas berkaitan dengan proses pengambilan keputusan dan tidak terkait dengan kekuatan sebagaimanahalnya kekuasaan. Kekuasaan terkait dengan kemampuan, sedangkan otoritas merupakan hak untuk mengambil tindakan yang diperlukan agar tugas dan tanggung jawab dapat dilaksanakan dengan baik. Otoritas dapat dirumuskan sebagai suatu tipe khusus dari kekuasaan yang secara asli melekat pada jabatan yang dimliki seorang pemimpin, ${ }^{10}$ sebagaimana ditampilkan dalam Gambar 1.

Otoritas (authority) atau wewenang dapat dirumuskan sebagai suatu tipe khusus dari kekuasaan yang secara asli melekat pada jabatan yang diduduki oleh pemimpin. Dengan demikian, otoritas adalah kekuasaan yang disahkan (legitimatized) oleh suatu peranan formal seseorang dalam suatu organisasi. ${ }^{11}$

${ }^{10}$ Husaini Usman, Manajemen: Teori, Praktek, dan Riset Pendidikan. Edisi 4 (Jakarta: Bumi Aksara, 2014), 416. Lebih jauh, Husaini beranggapan bahwa penggunaan kekuasaan selalu mengakibatkan perubahan sesorang atau kelompok ke suatu perubahan perilaku yang diinginkan. Perubahan ini dirumuskan sebagai pengaruh (influence). Jadi pengaruh itu lebih sempit daripada kekuasaan.

${ }^{11}$ Husaini Usman, Manajemen, 416. 

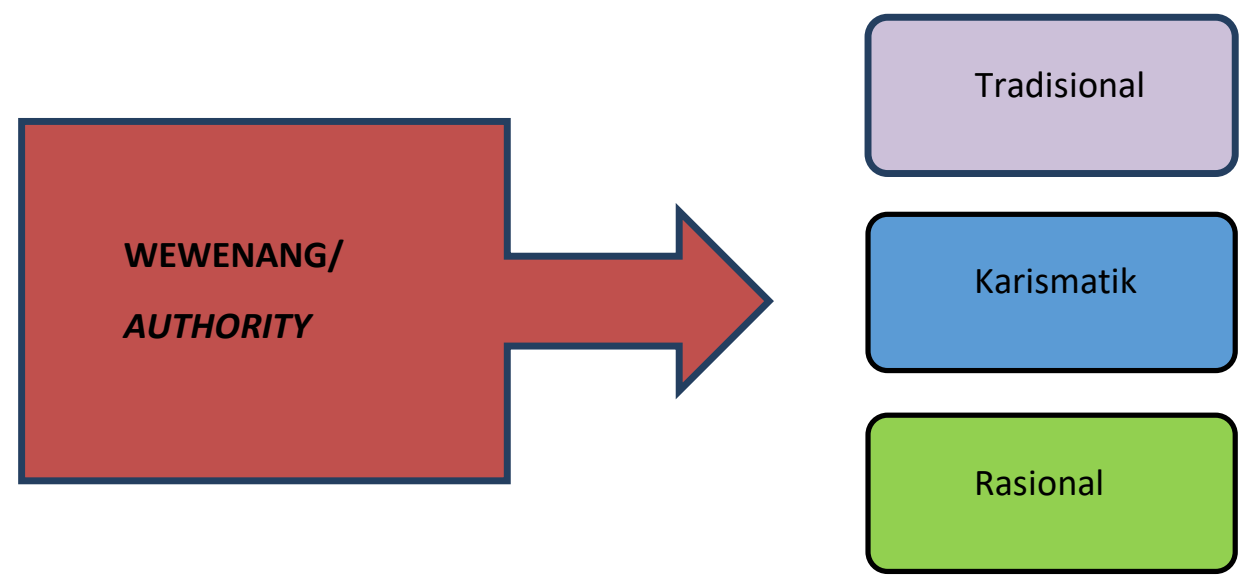

Gambar 1: Bentuk-bentuk Wewenang Menurut Max Weber

Max Weber mengidentifikasi beberapa tipe hubungan social yang terwujud dalam struktur otoritas yang mapan berdasarkan tindakan-tindakan social yang dilakukan bawahan terhadap perintah sesorang yang memiliki otoritas. Pertama adalah otoritas tradisional. Ia adalah bentuk wewenang atau otoritas yang berlandaskan pada kesakralan suatu tradisi tertentu yang menyebabkan individu patuh terhadap peraturan yang dibuat oleh pihak pemilik otoritas. Legitimasi ekuasaan dalam hal ini digunakan dengan pewarisan masa lalu dan masih dianggap berlaku ingga sekarang. Dalam hal ini bentuk hubungannya dengan bahwahan cenderung pada legitimasi hubungan keluarga. Contoh yang digambarkan di siini adalah kekuasaan Ratu Inggris yang dimiliki oleh keluarganya dalam system monarki. Weber melihat otoritas tradisional sebagai bentuk ketidakserataraan dalam masyarakat pra-modern yang diciptakan dan dipelihara meskipun hasilnya tidak rasional.

Kedua adalah otoritaskarismatik. Hal ini lebih didsarkan pada kualitas seorang pemimpin secara pribadi. Hal ini muncul oleh karena adanya sikap pada diri seseorang, seperi sikap heroic atau spiritual yang tinggi. Berbeda dengan otoritas tradisional yang muncul pada tatanan yang sudah mapan, otoritas model ini mempunyai kepercayaan khusus yang didukung oleh pengikutnya dalam rangka melegitimasi otoritas dengan menunjukkan kinerja leadership-nya. Otoritas ini seringkali dihubungkan dengan otoritas yang dimiliki oleh Bung Karno karena keistimewaan dan heroiknya dalam memperjuangkan proklamasi kemerdekaan dari penjajahan yang ada pada masanya. 
Ketiga adalah otoritas rasional. Kadang juga otoritas ini disebut dengan otoritas legal formal. Jenis otoritas ini ada oleh karena sesoerang mendapatkan posisi social yang sah dan sudah diatur dalam suatu peraturan yang juga sah. Sehingga otoritas rasional ini lebih banyak dikaitkan dengan peraturan-peratuan yang mengikat suatu masyarakat dan dijalankan secara bersama. Hal ini seringkali mengutamakan birokrasi yang punya struktur dan di dalamnya terdapat seperangkat peraturan dalam mengatur seluruh elemen individu yang ada di dalamnya. Jadi otoritas rasional dalam hal ini bersama dengan birokrasi menjadi bentuk pelaksanaan otoritas yang ada.

Keragaman etnis, budaya, keyakinan, dan rasial merupakan sunnatullah. Tuhan menggariskan hal ini melalui firmannya langsung dalam al-Qur'an. Keragaman adalah keniscayaan. Bahkan Tuhan tidak menginginkan keseragaman (wa lau sya'a rabbuka, laja'alannasa ummatan wahidah) Keragaman inilah sebenarnya anugerah terindah dari Allah subhanahu wa ta'ala kepada kita, khususnya di Negara kita Indonesia.

Negara kita merupakan salah satu Negara yang paling beragam di dunia. Keragaman merupakan potensi untuk menyatukan dalam bingkai lingkungan kebangsaan. Karenanya dibutuhkan cara pandang atau perspektif agar potensi ini sesuai dengan keinginan fitrah bersama, yaitu menjunjung tinggi kemanusiaan, kesetaraan, dan keadilan. Cara pandang inilah yang kemudian dikenal dengan istilah multikulturalisme. Sebuah sikap normatif di dalam merespon keragaman untuk kesetaraan dan ketunggal ika-an dalam kebhinnekaan.

Spirit kesatuan dalam kebhinnekaan sudah menjadi perspektif para pemimpin bangsa dari sejak dahulu kala. Karakter kepemimpinannya diletakkan dalam konteks kesadaran keragaman yang menjadi sunnatullah dalam bermasyarakat, berbangsa, dan bernegara. Landasan keragaman inilah yang menjadikan kekuasaan dan otoritas para founding fathers kita berjalan dinamis dan aktif. Pengaruh dan persuasi yang menjadi pengejewantahan dari kekuasaan selalu berjalan dalam konteks keragaman lingkungan.

Berangkat dari sebuah refleksi mendalam mengenai realitas yang beragam; kemudian akhirnya melahirkan slogan indah namun visioner jauh ke depan. Slogan yang sering kita kenal dengan nama "bhinneka tunggal ika" yang merupakan nilai luhur nenek moyang kita sekaligus mencerminkan karakter kepemimpinan yang kuat di 
dalam merespon keragaman baik budaya, etnis, rasial, dan keyakinan. Slogan ini dalam konteks Negara modern dikenal dengan istilah "unity in diversity" dengan berdasar pada kesetaraan dalam kewarganegaraan (citizenship)

Kewarganegaraan (citizenship) yang mengakui sekaligus melegitimasikan hak dan kebutuhan warganegara untuk mempertahankan komitmen mereka pada komunitas etnis dan budaya maupun pada national civic culture. Budaya warga negara nasional akan dianggap legitimate oleh semua warga negara, apabila budaya itu ditransformasikan dengan cara-cara yang mencerminkan dan yang menyuarakan keberagaman etnik, rasial, budaya, dan keyakinan sebagai unsur-unsur pembentuknya.

Salah satu asas dalam lingkungan yang beragam adalah kesetaraan. Kesetaraan merupakan prinsip hidup bersama dalam komunitas multicultural. Kesetaraan adalah esensi hidup free of disharmony dalam lingkungan multicultural. Kesetaraan perlu mengejewantah dalam dalam hak dan kewajiban. Suasana inilah yang akan melahirkan spiritualitas dalam kehidupan yang multicultural. Dalam konteks ini kemudian pendidikan multikultural menemukan relevansinya.

Pendidikan multikultural adalah proses pengembangan seluruh potensi manusia yang menghargai pluralitas dan heterogenitasnya sebagai konsekuensi dari keragaman budaya, etnis, suku, dan aliran (agama). Pendidikan multikultural menekankan sebuah filosofi pluralisme budaya ke dalam sistem pendidikan yang didasarkan pada prinsip-prinsip persamaan (equality), saling menghormati dan menerima serta memahami dan adanya komitmen moral untuk sebuah keadilan sosial. ${ }^{12}$

Jadi pendidikan multikultural dapat melahirkan kondisi saling menerima keragamaan yang kemudian akan melahirkan situasi keharmonisan social dalam wujud toleransi. Raihani ${ }^{13}$ dalam

${ }^{12}$ Rustam Ibahim, "Pendidikan Multikultural: Pengertian, Prinsip, dan Relevansinya dengan Tujuan Pendidikan Islam". Jurnal ADDIN, Vol. 7, No. 1 Februari 2013.

13 Raihani, A Whole School Approach: A Proposal for Education for Tolerance in Indonesia, (London: Sage Publications, 2013), 23. Raihani menyatakan: "What is meant by a whole-school approach includes the school's policies and vision, the quality of the curriculum and teaching, leadership and management, culture, student activities, and collaboration with the wider 
karyanya "A Whole School Approach: A Proposal for Education for Tolerance in Indonesia" menyatakan bahwa pendidikan toleransi seharusnya didekati secara holistic. Maksudnya adalah riset dan praktek dalam hal ini harus diarahkan pada sekolah secara keseluruhan (the whole school) bukan hanya pada bagian particular dari pengajaran dan pembelajaran di sekolah. Yang dimaksud dengan "a whole school approach" adalah meliputi visi dan kebijakan sekolah, kualitas kurikulum dan pengajaran, kepemimpinan dan manajemen, budaya, aktivitas siswa, dan kolaborasi dengan komunitas yang lebih luas.

Hal ini relevan juga dengan pondok pesantren. Pesantren dengan tradisi-nya masih menyimpan potensi multikultural. Kajiankajian dalam dunia pesantren selalu menekankan ketawadluan yang tinggi terhadap pandangan dan pendapat yang berbeda. Klaim kebenaran dan keselamatan (truth claim and salvation claim) selalu dinafikan dan setiap pendapat selalau diakhiri dengan kalimat "wallahu a'lamu bis shawab" yang meniscayakan ketiadaan klaim atau superiroritas kebenaran dari pada yang lainnya. Karakter berpikir ini yang kemudian membentuk sikap penghargaan yang tinggi terhadap local culture atau kearifan lokal, perbedaan, dan keragaman.

Hal ini juga bisa terlihat dari alumni pondok pesantren yang kemudianbanyak bergerak di wilayah gerakan moderatisme, toleransi, gender, dan isu-isu yang menjunjung tinggi nilai-nilai multikulturalisme. Pondok pesantren sebagai sub-kultur sekaligus sebagai satuan pendidikan dan penyelenggara pendidikan juga meniscayakan kesetaraan yang menjadi asas pokok dalam lingkungan multikultural. Karena ada spirit kesamaan dan kesetaraan inilah kemudian tercipta kebersamaan dan kesetiakawanan. Keragaman yang menjadi sunnatullah dalam konteks ini bisa menjadi katalisator dalam keharmonisan sosial. Ditambah lagi iklim pendidikan yang ada di dalamnya mendukung terciptanya keharmonisan dalam keragaman. Inilah sebenarnya hakekat dari pendidikan multikultural yang tidak hanya sekedar konsepsi teoritik namun juga praksis dalam kehidupan sehari-hari.

community, which all together contribute to the promotion and nurturance of tolerance within the school community." 


\section{Simpulan}

Kekuasaan (power) adalah kesempatan bagi individu atau sekelompok manusia untuk menyadarkan individu lainnya atau kelompok lainnya terhadap kemauan yang diinginkannya sekaligus pada saat yang bersamaan menerapkannya pada orang-orang yang sedang atau akan melakukan perlawanan kepadanya. Kekuasaan menjelma dalam bentuk, seperti, pengaruh, persuasi, manipulasi, kekuatan (force), dan koersi.

Sementara itu, otoritas merupakan wewenang yang diebrikan kepada sesorang atau kelompok atau instansi secara sah agar patuh terhadapnya karena didukung oleh norma dan peraturan yang dibuat. Jadi, kekuasaan terkait erat dengan kemampuan; sedangkan otoritas merupakan hak untuk mengambil tindakan yang diperlukan agar tugas dan tanggung jawab dapat dilaksanakan dengan baik.

Spirit kesatuan dalam kebhinnekaan sudah menjadi perspektif para pemimpin bangsa dari sejak dahulu kala, termasuk oleh kiai-kiai di pondok pesantren. Karakter kepemimpinan kiai di pondok pesantren diletakkan dalam konteks kesadaran keragaman yang menjadi sunnatullah dalam bermasyarakat, berbangsa, dan bernegara. Landasan keragaman inilah yang menjadikan kekuasaan dan otoritas para founding fathers kita berjalan dinamis dan aktif. Pengaruh dan persuasi yang menjadi pengejewantahan dari kekuasaan selalu berjalan dalam konteks keragaman lingkungan.

\section{Referensi}

Adair, John. Action Centred Leadership. Mumbai: Jaico Publishing House, 1970.

Bennis, Warren, On Becoming a Leader dan An Invented Life: Reflections on Leadership and Change. New York: Perseus Publishing, 1994.

Burlea Şchiopoiu A., Rainey S. Servant lider/Servant leadership, in Encyclopedia of Corporate Social Responsibility, Editor-in-Chief Samuel O. Idowu, Heidelberg: Springer-Verlag, 2013.

Ibrahim, Rustam, Pendidikan Multikultural: Pengertian, Prinsip, dan Relevansinya dengan Tujuan Pendidikan Islam. Jurnal ADDIN, Volume 7, No. 1 Februari 2013. 
JIEMAN: Journal of Islamic Educational Management

Karim, Mohammad. Pemimpin Transformasional di Lembaga Pendidikan Islam. Malang: UIN Maliki Press, 2010.

Khusnuridlo, Moh. Catatan Kuliah. Pada saat kuliah program Doktor Manajemen Pendidikan Islam di IAIN Pasca Sarjana dengan pokok bahasan "Kepemimpinan Spiritual dalam Islam: Refleksi Teologis tentang Power and Authority dalam Pendidikan Islam" pada Jumat, 29 Maret 2019.

Kymlicka, Will. Multicultural citizenship: A liberal Theory of Minority Rights. New York: Oxford University Press, 1995.

Raihani, Kepemimpinan Sekolah Transformatif. Yogyakarta: LkiS, 2010.

Raihani. A Whole School Approach: A Proposal for Education for Tolerance in Indonesia. London: Sage Publications, 2013.

Surya, Pribadi. Educational Management: Handbook for School of Education Student, Yogyakarta: Yogyakarta State University, 2011.

Usman, Husaini. Manajemen: Teori, Praktek, dan Riset Pendidikan. Edisi 4. Penerbit Bumi Aksara, 2014. 